\title{
Changes of cerebral regional oxygen saturation during pneumoperitoneum and Trendelenburg position under propofol anesthesia: a prospective observational study
}

Toru Matsuoka', Tadahiko Ishiyama ${ }^{2 *}$, Noriyuki Shintani ${ }^{2}$, Masakazu Kotoda ${ }^{1}$, Kazuha Mitsui ${ }^{2}$ and Takashi Matsukawa ${ }^{1}$

\begin{abstract}
Background: We evaluated the change of cerebral regional tissue oxygen saturation $\left(\mathrm{rSO}_{2}\right)$ along with the pneumoperitoneum and the Trendelenburg position. We also assessed the relationship between the change of $\mathrm{rSO}_{2}$ and the changes of mean arterial blood pressure (MAP), heart rate (HR), arterial carbon dioxide tension $\left(\mathrm{PaCO}_{2}\right)$, arterial oxygen tension $\left(\mathrm{PaO}_{2}\right)$, or arterial oxygen saturation $\left(\mathrm{SaO}_{2}\right)$.

Methods: Forty-one adult patients who underwent a robotic assisted endoscopic prostatic surgery under propofol and remifentanil anesthesia were involved in this study. During the surgery, a pneumoperitoneum was established using carbon dioxide. Measurements of $\mathrm{rSO}_{2}, \mathrm{MAP}, \mathrm{HR}, \mathrm{PaCO}_{2}, \mathrm{PaO}_{2}$, and $\mathrm{SaO}_{2}$ were performed before the pneumoperitoneum (baseline), every $5 \mathrm{~min}$ after the onset of pneumoperitoneum, before the Trendelenburg position. After the onset of the Trendelenburg position, $\mathrm{rSO}_{2}, \mathrm{MAP}$, $\mathrm{HR}$ were recorded at 5, 10, 20, 30, 45, and 60 min, and $\mathrm{PaCO}_{2}, \mathrm{PaO}_{2}$, and $\mathrm{SaO}_{2}$ were measured at 10,30, and 60 min.

Results: Before the pneumoperitoneum, left and right $\mathrm{rSO}_{2}$ were $67.9 \pm 6.3 \%$ and $68.5 \pm 7.0 \%$. Ten minutes after the onset of pneumoperitoneum, significant increase in the $\mathrm{rSO}_{2}$ was observed (left: $69.6 \pm 5.9 \%$, right: $70.6 \pm 7.4 \%$ ). During the Trendelenburg position, the $\mathrm{rSO}_{2}$ increased initially and peaked at 5 min (left: $72.2 \pm 6.5 \%$, right: $73.1 \pm 7.6 \%$ ), then decreased. Multiple regression analysis showed that change of $\mathrm{rSO}_{2}$ correlated with $\mathrm{MAP}$ and $\mathrm{PaCO}_{2}$.
\end{abstract}

Conclusions: Pneumoperitoneum and the Trendelenburg position in robotic-assisted endoscopic prostatic surgery did not worsen cerebral oxygenation. Arterial blood pressure is the critical factor in cerebral oxygenation.

Trial registration: Japan Primary Registries Network (JPRN); UMIN-CTR ID; UMIN000026227 (retrospectively registered).

Keywords: Cerebral oxygenation, Endoscopic prostatic surgery, Pneumoperitoneum, Trendelenburg position

\footnotetext{
* Correspondence: ishiyama@yamanashi.ac.jp

${ }^{2}$ Surgical Center, University of Yamanashi Hospital, University of Yamanashi,

1110 Shimokato, Chuo, Yamanashi 409-3898, Japan

Full list of author information is available at the end of the article
}

(c) The Author(s). 2019 Open Access This article is distributed under the terms of the Creative Commons Attribution 4.0 International License (http://creativecommons.org/licenses/by/4.0/), which permits unrestricted use, distribution, and reproduction in any medium, provided you give appropriate credit to the original author(s) and the source, provide a link to the Creative Commons license, and indicate if changes were made. The Creative Commons Public Domain Dedication waiver (http://creativecommons.org/publicdomain/zero/1.0/) applies to the data made available in this article, unless otherwise stated. 


\section{Background}

In robotic-assisted endoscopic prostatic surgery, a carbon dioxide pneumoperitoneum and the Trendelenburg position are essential. In the pneumoperitoneum and the Trendelenburg position, intracranial pressure was reported to increase [1]. In addition, pneumoperitoneum increases intraperitoneal pressure that leads to increase in intrathoracic pressure. Furthermore, the Trendelenburg position increases intrathoracic pressure. Increase in intrathoracic pressure should result in increase in central venous pressure [2]. Both intracranial pressure and central venous pressure increase in the pneumoperitoneum and the Trendelenburg position. The cerebral perfusion pressure is regarded as the mean arterial blood pressure (MAP) minus the intracranial pressure (when intracranial pressure $>$ central venous pressure) or the central venous pressure (when central venous pressure $>$ intracranial pressure) [3]. Therefore, unless the MAP changes the cerebral perfusion pressure decreased and cerebral circulation might be impaired in the pneumoperitoneum combined with the Trendelenburg position. Nevertheless, cerebral blood flow is maintained constantly within a wide range of cerebral perfusion pressure that is known as cerebral autoregulation [4]. On the other hand, cerebral blood flow has been reported to fluctuate even within autoregulation [5]. Therefore, cerebral blood flow may be unchanged or reduced after the pneumoperitoneum and the Trendelenburg position.

Measurement of cerebral regional tissue oxygen saturation values $\left(\mathrm{rSO}_{2}\right)$ using near infrared spectroscopy can allow to assess cerebral circulation [6]. A previous study investigated that cerebral oxygenation during pneumoperitoneum in the Trendelenburg position [7]. However, the Trendelenburg position was firstly placed followed by pneumoperitoneum in that study. In robotic-assisted endoscopic prostatic surgery, pneumoperitoneum is performed before the Trendelenburg position.

We tested the following hypotheses. Firstly, $\mathrm{rSO}_{2}$ does not change after the pneumoperitoneum. Secondary, the Trendelenburg position combined with pneumoperitoneum does not alter $\mathrm{rSO}_{2}$. The primary outcome was the change of $\mathrm{rSO}_{2}$ along with the pneumoperitoneum and postural change. The secondary outcome was the relationship between the change of $\mathrm{rSO}_{2}$ and MAP, heart rate $(\mathrm{HR})$, arterial carbon dioxide tension $\left(\mathrm{PaCO}_{2}\right)$, arterial oxygen tension $\left(\mathrm{PaO}_{2}\right)$, or arterial oxygen saturation $\left(\mathrm{SaO}_{2}\right)$.

\section{Methods}

This study was approved by the institutional review board of University of Yamanashi (study No. 488), and and was registered in the University Hospital Medical Information Network Clinical Trials Registry (UMIN-CTR) under study number UMIN000026227. Written informed consent was obtained from all patients.

\section{Anesthesia}

Fifty-six adult patients (ASA physical status I or II) who underwent robotic-assisted endoscopic prostatic surgery were recruited. Patients having history of cerebral diseases such as cerebral infarction, cerebral hemorrhage, transient ischemic attack, or subarachnoid hemorrhage were excluded. No premedication was given. In the operating room, two sensors of near infrared spectroscopy (SAFB-SM, Covidien, Dublin, Ireland) were attached on the patient's forehead to measure the left and right $\mathrm{rSO}_{2}$. A pulse oximeter was used to monitor percutaneous arterial oxygen saturation $\left(\mathrm{SpO}_{2}\right)$. A bispectral index (BIS) sensor was also attached on the forehead (Model QUATRO, Covidien). An earphone-type infrared tympanic thermometer (CE Thermo, Nipro, Tokyo, Japan) was used to monitor body temperature. Non-invasive arterial blood pressure, $\mathrm{HR}, \mathrm{rSO}_{2}, \mathrm{SpO}_{2}$, and body temperature were measured before induction of general anesthesia while the patient breathed room air (Pre values). Fluid was infused at $6 \mathrm{ml} / \mathrm{kg} / \mathrm{hr}$. Anesthesia was induced and maintained with propofol using target controlled infusion and remifentanil. Tracheal intubation was facilitated with rocuronium. After the induction of anesthesia, radial arterial catheter was placed to allow continuous monitoring of MAP and blood gas analysis $\left(\mathrm{SaO}_{2}\right.$, $\mathrm{PaO}_{2}$, and $\mathrm{PaCO}_{2}$ ). The patient's lungs were mechanically ventilated in a volume controlled mode (tidal volume: $6-8 \mathrm{ml} / \mathrm{kg}$ ) with a positive end-expiratory pressure of $3 \mathrm{~cm} \mathrm{H}_{2} \mathrm{O}$. Peak airway pressure was controlled below 22 $\mathrm{cmH}_{2} \mathrm{O} \cdot \mathrm{PaCO}_{2}$ was maintaind between 35 and $45 \mathrm{mmHg}$. Fraction of inspired oxygen was adjusted to maintain $\mathrm{PaO}_{2}$ between 150 and $250 \mathrm{mmHg}$. Position of the blood pressure transducer was standardized to place at the level of the ear for every patient. Mean arterial blood pressure was controlled within $60-120 \mathrm{mmHg}$. If MAP fell below $60 \mathrm{mmHg}$, ephedrine or phenylephrine was given. If MAP went up over $120 \mathrm{mmHg}$, the infusion rate of remifentanil was increased. Bispectral index (BIS) was adjusted between 40 and 60 by controlling the target of propofol infusion. If $\mathrm{rSO}_{2}$ went down below $50 \%$, or by $20 \%$ of the preanesthetic value, inspired oxygen was increased.

\section{Measurements}

Before pneumoperitoneum, baseline measurements of $\mathrm{rSO}_{2}, \mathrm{MAP}, \mathrm{HR}, \mathrm{SpO}_{2}, \mathrm{SaO}_{2}, \mathrm{PaO}_{2}$, and $\mathrm{PaCO}_{2}$ were made. Pneumoperitoneum with intra-abdominal pressure of $10-15 \mathrm{mmHg}$ was established and measurements were repeated every $5 \mathrm{~min}$. Approximately $15 \mathrm{~min}$ after the establishment of the pneumoperitoneum, the Trendelenburg position with $30^{\circ}$ head-down tilt was started. Before the start of the Trendelenburg position, $\mathrm{rSO}_{2}, \mathrm{MAP}, \mathrm{HR}, \mathrm{SpO}_{2}$, $\mathrm{SaO}_{2}, \mathrm{PaO}_{2}$, and $\mathrm{PaCO}_{2}$ were measured. Measurements of $\mathrm{rSO}_{2}, \mathrm{MAP}, \mathrm{HR}$, and $\mathrm{SpO}_{2}$ were made at 5, 10, 20, 30, 45, $60 \mathrm{~min}$ after the start of Trendelenburg position. After the 
onset of the Trendelenburg position, blood gas analysis was performed at 10, 30, $60 \mathrm{~min}$. The measurements were not blinded to the anesthesiologists.

\section{Statistical analysis}

We used Stat Flex version 6.0 (Artec, Osaka, Japan) for statistical analysis. Power analysis revealed that the sample size of 41 patients was sufficient to provided $80 \%$ power with an $\alpha$ level of 0.05 to detect mean differences of $5 \%$ in $\mathrm{rSO}_{2}$. Change in $\mathrm{rSO}_{2}, \mathrm{MAP}, \mathrm{HR}, \mathrm{SpO}_{2}, \mathrm{SaO}_{2}$, $\mathrm{PaO}_{2}$, and $\mathrm{PaCO}_{2}$ were examined via analysis of variance and Tukey post hoc comparisons. Multiple regression analysis was performed to estimate the relationship between $\mathrm{rSO}_{2}$ and $\mathrm{MAP}, \mathrm{HR}, \mathrm{SpO}_{2}, \mathrm{SaO}_{2}, \mathrm{PaO}_{2}$, or $\mathrm{PaCO}_{2}$. For multiple regression analysis, $\mathrm{rSO}_{2}$ data were averaged. When statistical significances were obtained after the multiple regression analysis, we performed linear regression analysis. Values are represented as means \pm SDs; a $p$ value $<0.05$ was considered statistically significant.

\section{Results}

Of 56 eligible patients, two patients failed to meet the inclusion criteria, and 13 patients developed the protocol fault such as data acquisition failure $(n=8)$, position of blood pressure transducer error $(n=2)$, and blood pressure measurement failure (bending of the arterial catheter) $(n=3)$. Therefore, we enrolled 41 patients (Fig. 1). Patients' age, height, weight, body mass index (BMI) were $67 \pm 6$ yr., $164.8 \pm 6.0 \mathrm{~cm}, 64.4 \pm 9.2 \mathrm{~kg}$, and $23.7 \pm 2.9 \mathrm{~kg} / \mathrm{m}^{2}$, respectively. One patient has BMI over $30 \mathrm{~kg} / \mathrm{m}^{2}\left(30.6 \mathrm{~kg} / \mathrm{m}^{2}\right)$. No patients have comorbidities such as chronic obstructive pulmonary disease, heart failure, or uncontrolled hypertension. BIS before anesthesia was $93 \pm 6$. Propofol was infused at $2.8 \pm 0.5 \mu \mathrm{g} /$ $\mathrm{ml}$ and remifentanil was infused at $0.37 \pm 0.10 \mu \mathrm{g} / \mathrm{kg} / \mathrm{min}$. BIS was maintained at $44 \pm 6$ during the study period. Body temperature before anesthesia was $36.3 \pm 0.4{ }^{\circ} \mathrm{C}$, and was maintained at $36.5 \pm 0.5^{\circ} \mathrm{C}$ during the study period.

Mean arterial blood pressure before anesthesia was $95 \pm 9 \mathrm{mmHg}$. There were 8 patients who developed hypotension (MAP below $60 \mathrm{mmHg}$ ) after the induction of anesthesia. They were treated with ephedrine $5 \mathrm{mg}$ and phenylephrine $0.05 \mathrm{mg}$. As shown in Fig. 2a, MAP decreased to $67 \pm 10 \mathrm{mmHg}$ before the pneumoperitoneum, and increased significantly after the pneumoperitoneum $(81 \pm 13 \mathrm{mmHg})$. After the Trendelenburg position, MAP slightly increased by $3 \mathrm{mmHg}$ but the change was not statistically significant. Then it decreased significantly at 30, 45, and $60 \mathrm{~min}$ after the Trendelenburg position

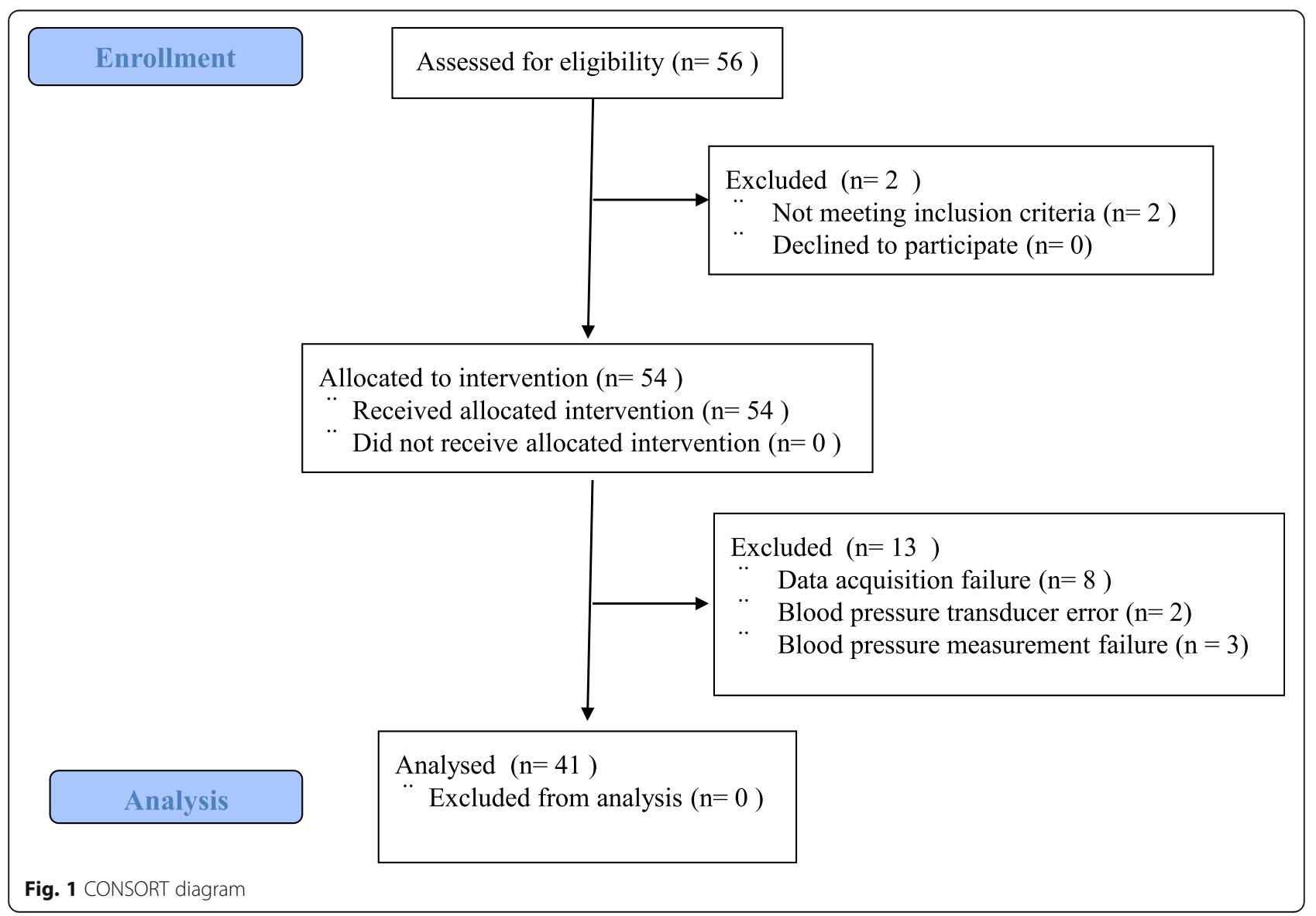



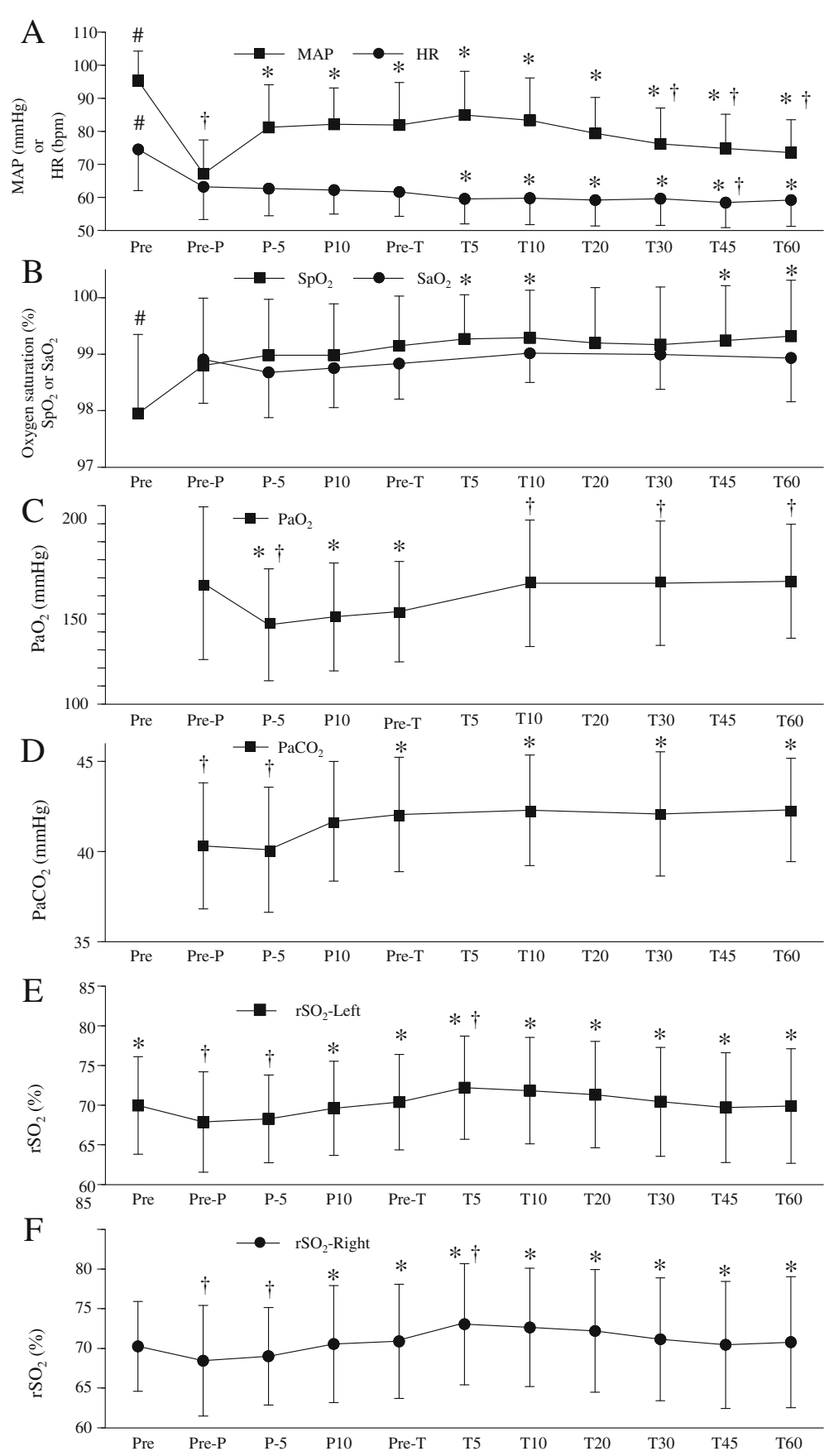

Fig. 2 a Changes in mean arterial blood pressure (MAP) and heart rate (HR). b Changes in percutaneous $\left(\mathrm{SpO}_{2}\right)$ and arterial $\left(\mathrm{SaO}_{2}\right)$ oxygen saturation. c Changes in arterial oxygen tension $\left(\mathrm{PaO}_{2}\right)$. $\mathbf{d}$ Changes in carbon dioxide tension $\left(\mathrm{PaCO}_{2}\right)$. e Changes in left cerebral regional oxygen saturation $\left(\mathrm{rSO}_{2}\right)$. $\mathbf{f}$ Changes in right cerebral regional oxygen saturation $\left(\mathrm{rSO}_{2}\right)$. Pre: before the induction of anesthesia, Pre-P: just before the pneumoperitoneum, $\mathrm{P}-5$, 10: 5, 10 min after the pneumoperitoneum, Pre-T: just before the Trendelenburg position (approximately 15 min after the pneumoperitoneum), T-5, 10, $20,30,45,60: 5,10,20,30,45,60$ min after the Trendelenburg position. ${ }^{*} P<0.05$, compared with Pre-P, $+p<0.05$, compared with Pre-T, \# $P<0.05$, compared with other time points 
compared with that before the Trendelenburg position. Heart rate before anesthesia was $75 \pm 12$ beats $/ \mathrm{min}$. It decreased to $63 \pm 10$ beats/min before the pneumoperitoneum. Heart rate from $10 \mathrm{~min}$ to $60 \mathrm{~min}$ after the Trendelenburg position significantly decreased compared with that at before pneumoperitoneum (Fig. 2a). $\mathrm{SpO}_{2}$ before anesthesia (Pre) was $98.0 \pm 1.4 \%$, and increased to $99.0 \pm 1.0 \%$ throughout the study period (Fig. 2b). $\mathrm{SaO}_{2}$ did not change in this study (Fig. 2b).

$\mathrm{PaO}_{2}$ before the pneumoperitoneum was $167.4 \pm 43.9$ mmHg. $\mathrm{PaO}_{2}$ decreased after the pneumoperitoneum, and increased after the Trendelenburg position. $\mathrm{PaCO}_{2}$ before the pneumoperitoneum was $40.3 \pm 3.5 \mathrm{mmHg}$ (Fig.2c). $\mathrm{PaCO}_{2}$ slightly but significantly increased after the pneumoperitoneum. $\mathrm{PaCO}_{2}$ remained high level during the pneumoperitoneum combined with the Trendelenburg position (Fig.2d).

Before general anesthesia, left (Fig.2e) and right (Fig.2f) $\mathrm{rSO}_{2}$ were $70.0 \pm 6.2 \%$ and $70.3 \pm 5.6 \%$, respectively. Before the pneumoperitoneum, left and right $\mathrm{rSO}_{2}$ decreased to $67.9 \pm 6.3 \%$ and $68.5 \pm 7.0 \%$. Ten min after the pneumoperitoneum, left and right $\mathrm{rSO}_{2}$ significantly increased to $69.6 \pm 5.9 \%$ and $70.6 \pm 7.4 \%$. While patients were in the Trendelenburg position, left and right $\mathrm{rSO}_{2}$ significantly increased temporarily ( $5 \mathrm{~min}$ after the Trendelenburg position), and decreased to the baseline value afterwards but the change was not statistically significant.

Multiple regression analysis showed that change of $\mathrm{rSO}_{2}$ was correlated with MAP $(p<0.05)$ and $\mathrm{PaCO}_{2}(p<0.0001)$ (Table 1). Linear regression analysis revealed that $\mathrm{rSO}_{2}=$ $65.717+0.0558 \times$ MAP, $\mathrm{r}=0.1141$ (95\% confidence interval; $0.0059-0.2197)$, and $\mathrm{rSO}_{2}=45.3682+0.60127 \times \mathrm{PaCO}_{2}$, $\mathrm{r}=0.3059$ (95\% confidence interval; 0.2037-0.4015).

Table 1 Multiple regression analysis between $\mathrm{rSO}_{2}$ and MAP, $\mathrm{HR}, \mathrm{SpO}_{2}, \mathrm{SaO}_{2}, \mathrm{PaO}_{2}$, or $\mathrm{PaCO}_{2}$

\begin{tabular}{lllllll}
\hline & \multicolumn{2}{l}{$\begin{array}{l}\text { Unstandardized } \\
\text { coefficients }\end{array}$} & & $\begin{array}{l}\text { Standardized } \\
\text { coefficients }\end{array}$ & $t$ & $\begin{array}{l}p- \\
\text { value }\end{array}$ \\
\cline { 2 - 3 } & $\mathrm{B}$ & $\mathrm{SE}$ & & $\beta$ & & \\
\hline $\mathrm{MAP}$ & 83.0782 & 70.0290 & & & \\
$\mathrm{HR}$ & 0.07342 & 0.03057 & 0.1364 & 2.40144 & 0.0170 \\
$\mathrm{SpO}_{2}$ & -0.61319 & 0.04505 & 0.0168 & 0.29271 & 0.7700 \\
$\mathrm{SaO}_{2}$ & 0.13072 & 0.75372 & 0.0144 & 0.17343 & 0.8624 \\
$\mathrm{PaO}_{2}$ & 0.01468 & 0.01322 & 0.0813 & 1.1022 & 0.2679 \\
$\mathrm{PaCO}_{2}$ & 0.61094 & 0.11081 & 0.3222 & 5.51332 & 0.0000 \\
\hline
\end{tabular}

Change of $\mathrm{rSO}_{2}$ was correlated with MAP $(p<0.05)$ and $\mathrm{PaCO}_{2}(p<0.0001)$

$\mathrm{rSO}_{2}$ cerebral regional tissue oxygen saturation, MAP mean arterial blood pressure, $H R$ heart rate, $\mathrm{SpO}_{2}$ percutaneous arterial oxygen saturation, $\mathrm{SaO}_{2}$ arterial oxygen saturation, $B$ regression coefficient, $S E$ standard error, $\beta$ standardized partial regression coefficient

\section{Discussion}

We found in the present study that $\mathrm{rSO}_{2}$ increased after the pneumoperitoneum and further increased temporarily after the steep Trendelenburg position, and decreased afterwards. These changes were along with the alteration of MAP and $\mathrm{PaCO}_{2}$. However, the changes did not correlate with the changes of $\mathrm{HR}, \mathrm{PaO}_{2}$, or $\mathrm{SaO}_{2}$.

The cerebral perfusion pressure is regarded as MAP minus central venous pressure (or intracranial pressure) [3]. A previous study reported that central venous pressure increased by $2-5 \mathrm{mmHg}$ during the pneumoperitoneum $[8,9]$. On the other hand, another previous study reported that MAP did not change after the pneumoperitoneum [9]. Thus, cerebral perfusion pressure should slightly decrease after the pneumoperitoneum. Contrary to the previous study [9], another study reported that pneumoperitoneum with a consequent increase in intracranial pressure produced systemic hypertension. [10]. Our study concurs with the latter study that MAP increased after the pneumoperitoneum. In patients in this study, cerebral autoregulation should be intact. Owing to the cerebral autoregulation, the cerebral blood flow is maintained constantly within a wide range of cerebral perfusion pressure. It is reasonable to assume that cerebral perfusion pressure remained normal level after the pneumoperitoneum. $\mathrm{rSO}_{2}$ reflects cerebral perfusion [11]. Therefore, we assumed that $\mathrm{rSO}_{2}$ would be unchanged after the pneumoperitoneum. However, $\mathrm{rSO}_{2}$ increased after the pneumoperitoneum in this study. In steady state, cerebral blood flow is maintained constant with static cerebral autoregulation [4]. In acute change in blood pressure, cerebral blood flow is compensatory adjusted by dynamic cerebral autoregulation $[12,13]$. However, there is a time lag between the rise in blood pressure and the activation of dynamic cerebral autoregulation [14]. If blood pressure increased suddenly, cerebral blood flow may increase transiently. As a result, $\mathrm{rSO}_{2}$ increased.

After the Trendelenburg position combined with $\mathrm{CO}_{2}$ pneumoperitoneum, $\mathrm{rSO}_{2}$ increased initially. Some studies reported that central venous pressure increased by 10-16 mmHg during the Trendelenburg position combined with $\mathrm{CO}_{2}$ pneumoperitoneum [15-17]. On the other hand, blood pressure also increased by $10-15 \mathrm{mmHg}$ during the Trendelenburg position combined with $\mathrm{CO}_{2}$ pneumoperitoneum in the previous studies $[2,15,17]$. In agreement with those studies, we observed that MAP increased by $16-18 \mathrm{mmHg}$ at $5-10 \mathrm{~min}$ after the Trendelenburg position combined with $\mathrm{CO}_{2}$ pneumoperitoneum compared with that before the pneumoperitoneum. Change in cerebral perfusion pressure immediately after the Trendelenburg position was $16-18 \mathrm{mmHg}$ (MAP change) minus $10-16 \mathrm{mmHg}$ (assumed CVP change) [15-17]. The value was $0-8 \mathrm{mmHg}$. Whereas change in cerebral 
perfusion pressure after pneumoperitoneum was $14 \mathrm{mmHg}$ (MAP change) minus $2-5 \mathrm{mmHg}$ (assumed CVP change) $[8,9]$. The value was $9-12 \mathrm{mmHg}$. Therefore, it is assumed that the cerebral perfusion pressure did not increase after the Trendelenburg position compared with that at the $\mathrm{CO}_{2}$ pneumoperitoneum. Cerebral perfusion pressure was not involved in the transient increase in $\mathrm{rSO}_{2}$ just after the Trendelenburg position combined with $\mathrm{CO}_{2}$ pneumoperitoneum. Schramm et al. reported that cerebral autoregulation deteriorated with Trendelenburg position combined with pneumoperitoneum [18]. Garrett et al. [19] reported that the cerebral blood flow velocity decreased when the posture was changed from the supine to the seated position. Postural change influences cerebral blood flow. Based on those previous studies, cerebral blood flow increased temporarily when the posture was changed from the supine to the Trendelenburg position. Due to transient increase in cerebral blood flow, $\mathrm{rSO}_{2}$ initially increased after the Trendelenburg position combined with $\mathrm{CO}_{2}$ pneumoperitoneum.

Cerebral blood flow varies with $\mathrm{PaCO}_{2}$. We recently reported that changes in $\mathrm{rSO}_{2}$ significantly correlated with changes in $\mathrm{PaCO}_{2}$. [20]. Abdominally insufflated carbon dioxide is absorbed into systemic circulation and is exhaled with ventilation. We attempted to adjust tidal volume and respiratory rate to maintain $\mathrm{PaCO}_{2}$ at $40 \pm$ $5 \mathrm{mmHg}$. However, $\mathrm{PaCO}_{2}$ increased significantly after the pneumoperitoneum. Thus, $\mathrm{rSO}_{2}$ increased along with the rise in $\mathrm{PaCO}_{2} \cdot \mathrm{rSO}_{2}$ gradually decreased after the pneumoperitoneum combined with the Trendelenburg position. Nevertheless, $\mathrm{PaCO}_{2}$ remained high level during the pneumoperitoneum combined with the Trendelenburg position. Although there was a correlation between $\mathrm{rSO}_{2}$ and $\mathrm{PaCO}_{2}, \mathrm{PaCO}_{2}$ may be less involved in the change of $\mathrm{rSO}_{2}$. On the other hand, MAP was observed highest at $5 \mathrm{~min}$ after the Trendelenburg position ( $\mathrm{T} 5 \mathrm{in}$ the Fig. 2a) and it decreased thereafter. Head-down position in combination with a pneumoperitoneum impairs cerebral autoregulation over time [18]. It is likely that $\mathrm{rSO}_{2}$ changes with alterations in mean blood pressure rather than change of $\mathrm{PaCO}_{2}$.

Cerebral oxygenation can be monitored by $\mathrm{rSO}_{2}$ [21]. Cerebral oxygenation may influence the change of $\mathrm{rSO}_{2}$ in this study. According to the manufacturer, $\mathrm{rSO}_{2}$ reflects $25 \%$ arterial and $75 \%$ venous portion of blood. If cerebral oxygen consumption decreased, venous blood oxygen could be increased. As a result, $\mathrm{rSO}_{2}$ may have increased. However, BIS was unchanged after the induction of anesthesia. There were no factors that involved the decline in cerebral oxygen consumption after the pneumoperitoneum. Furthermore, $\mathrm{PaO}_{2}$ was significantly decreased after pneumoperitoneum. Therefore, oxygenation status was unlikely to participate in the rise of $\mathrm{rSO}_{2}$.
In this study, data before anesthesia were obtained under room air breathing and other data were measured under oxygen inspiration. Therefore, arterial oxygen saturation before anesthesia was significantly lower than that after the induction of anesthesia. However, $\mathrm{rSO}_{2}$ before anesthesia was significantly higher than that after the induction of anesthesia. Mean arterial blood pressure also declined after the induction of anesthesia. In addition, cerebral metabolic rate decreases after the induction of anesthesia that results in decrease in cerebral blood flow [22]. This phenomenon may indicate that $\mathrm{rSO}_{2}$ is firmly affected by MAP and cerebral blood flow rather than arterial oxygenation status in this study situation.

Cerebral autoregulation, which is expected to keep cerebral blood flow constant, mainly depends on cerebral perfusion pressure [4]. If cerebral perfusion pressure were too low (below the lower limit of autoregulation), cerebral blood flow might depend on MAP [23]. When the cerebral perfusion pressure was below the lower limit of autoregulation, cerebral blood flow should have been changed directly with the fluctuation of MAP. In this situation, $\mathrm{rSO}_{2}$ altered along with the change of MAP though decrease in blood pressure below the lower limit of autoregulation was not observed in this study. Nevertheless, individual variation in MAP while anesthetized and the lower limit of autoregulation might make the $\mathrm{rSO}_{2}$-MAP relationship different for different individuals.

In this study, $\mathrm{PaO}_{2}$ decreased after pneumoperitoneum. A previous study suggested that pneumoperitoneum elevated diaphragm that can lead to basilar atelectasis, with resulting right to left shunt formation [24]. Atelectasis caused by pneumoperitoneum may contribute to the decrease of $\mathrm{PaO}_{2}$. After the Trendelenburg position, $\mathrm{PaO}_{2}$ increased. Some studies reported that peak and mean airway pressure increased after the Trendelenburg position $[25,26]$. Elevated airway pressure may have contributed to reduce atelectasis. As a result, $\mathrm{PaO}_{2}$ increased.

This study has some limitations. First, we did not measure central venous pressure because central venous catheterization is an invasive method and not always necessary for robotic-assisted endoscopic prostatic surgery. In many studies, central venous pressure was increased after pneumoperitoneum [8,9] and the Trendelenburg position combined with pneumoperitoneum. [15-17] Therefore, the present study was based on an assumption that central venous pressure increased in this study. Second, cerebral blood flow was not measured. Transcranial Doppler can be utilized to assess the cerebral blood flow. However, due to the protection pads that supported the patient during the surgery, there was no space on the patient's head for the Doppler probe attachment. Third, extracranial contamination affects $\mathrm{rSO}_{2}$. Davie et al. reported that the extracranial contamination 
potentially affected $\mathrm{rSO}_{2}$ [27]. They also indicated that forehead skin blood made an impact on $\mathrm{rSO}_{2}$ [27]. Trendelenburg position may cause venous stasis, which could result in the increase of venous portion of blood. Therefore, Trendelenburg position may have affected the relative arterial and venous content of the forehead skin blood. Extracranial contamination might have influenced $\mathrm{rSO}_{2}$ in this study.

\section{Conclusions}

In conclusion, pneumoperitoneum and the Trendelenburg position in robotic-assisted endoscopic prostatic surgery did not aggravate cerebral oxygenation. Changes in $\mathrm{rSO} 2$ were associated with the alteration of MAP and $\mathrm{PaCO} 2$, but did not correlate with the changes of $\mathrm{HR}, \mathrm{PaO} 2$, or $\mathrm{SaO} 2$, indicating that arterial blood pressure is the critical factor in the cerebral oxygenation.

\section{Abbreviations \\ BIS: Bispectral index; HR: Heart rate; MAP: Mean arterial blood pressure; $\mathrm{PaCO}_{2}$ : Arterial carbon dioxide tension; $\mathrm{PaO}_{2}$ : Arterial oxygen tension; $\mathrm{rSO}_{2}$ : Cerebral regional tissue oxygen saturation; $\mathrm{SaO}_{2}$ : Arterial oxygen saturation; $\mathrm{SpO}_{2}$ : Percutaneous arterial oxygen saturation}

\section{Acknowledgements}

Not applicable

\section{Funding}

Support was provided solely from institutional and departmental sources. None of the authors has a personal financial interest related to this research.

\section{Availability of data and materials}

The datasets used and analyzed during the current study are available from the corresponding author on reasonable request.

\section{Authors' contributions}

TM conducted the study, acquired the data, and wrote the draft of manuscript. TI designed the study, analyzed and interpreted the data, wrote the manuscript, and is the corresponding author. NS acquired the data, reviewed the analysis, interpreted the data, and revised the manuscript. MK interpreted the data, and revised the manuscript. KM interpreted the data, and revised the manuscript. TM interpreted the data, and revised the manuscript. All authors read and approved the final manuscript.

\section{Ethics approval and consent to participate}

This study was approved by the institutional review board of University of Yamanashi (study No. 488), and and was registered in the University hospital Medical Information Network Clinical Trials Registry (UMIN-CTR) under study number UMIN000026227. Written informed consent was obtained from all patients. Name of the ethics committee: The review board of University of Yamanashi. Reference number: No 488.

\section{Consent for publication}

Not applicable

\section{Competing interests}

The authors declare that they have no competing interests.

\section{Publisher's Note}

Springer Nature remains neutral with regard to jurisdictional claims in published maps and institutional affiliations.

\section{Author details}

'Department of Anesthesiology, Faculty of Medicine, University of Yamanashi, Chuo, Yamanashi, Japan. ${ }^{2}$ Surgical Center, University of
Yamanashi Hospital, University of Yamanashi, 1110 Shimokato, Chuo, Yamanashi 409-3898, Japan.

Received: 1 June 2018 Accepted: 18 April 2019

Published online: 15 May 2019

\section{References}

1. Halverson A, Buchanan R, Jacobs L, Shayani V, Hunt T, Riedel C, et al. Evaluation of mechanism of increased intracranial pressure with insufflation. Surg Endosc. 1998;12:266-9.

2. Kalmar AF, Foubert L, Hendrickx JF, Mottrie A, Absalom A, Mortier EP, et al. Influence of steep Trendelenburg position and $\mathrm{CO}_{2}$ pneumoperitoneum on cardiovascular, cerebrovascular, and respiratory homeostasis during robotic prostatectomy. Br J Anaesth. 2010;104:433-9.

3. Munis JR, Lozada LJ. Giraffes, siphons, and starling resistors. Cerebral perfusion pressure revisited. J Neurosurg Anesthesiol. 2000;12:290-6.

4. Paulson OB, Strandgaard S, Edvinsson L. Cerebral autoregulation. Cerebrovasc Brain Metab Rev. 1990:2:161-92.

5. Tzeng YC, Ainslie PN. Blood pressure regulation IX: cerebral autoregulation under blood pressure challenges. Eur J Appl Physiol. 2014;114:545-59.

6. Ali AM, Green D, Zayed H, Halawa M, El-Sakka K, Rashid HI. Cerebral monitoring in patients undergoing carotid endarterectomy using a triple assessment technique. Interact Cardiovasc Thorac Surg. 2011;12:454-7.

7. Park EY, Koo BN, Min KT, Nam SH. The effect of pneumoperitoneum in the steep Trendelenburg position on cerebral oxygenation. Acta Anaesthesiol Scand. 2009:53:895-9.

8. Andersson L, Wallin CJ, Sollevi A, Odeberg-Wernerman S Pneumoperitoneum in healthy humans does not affect central blood volume or cardiac output. Acta Anaesthesiol Scand. 1999:43:809-14.

9. Hänel F, Blobner M, Bogdanski R, Werner C. Effects of carbon dioxide pneumoperitoneum on cerebral hemodynamics in pigs. J Neurosurg Anesthesiol. 2001;13:222-6.

10. Ben-Haim M, Mandeli J, Friedman RL, Rosenthal RJ. Mechanisms of systemic hypertension during acute elevation of intraabdominal pressure. J Surg Res. 2000;91:101-5.

11. Rigamonti A, Scandroglio M, Minicucci F, Magrin S, Carozzo A, Casati A. A clinical evaluation of near-infrared cerebral oximetry in the awake patient to monitor cerebral perfusion during carotid endarterectomy. J Clin Anesth. 2005:17:426-30.

12. Kurazumi T, Ogawa Y, Yanagida R, Morisaki H, Iwasaki Kl. Dynamic cerebral autoregulation during the combination of mild hypercapnia and cephalad fluid shift. Aerosp Med Hum Perform. 2017;88:819-26.

13. Zhang $\mathrm{R}$, Zuckerman JH, Giller CA, Levine BD. Transfer function analysis of dynamic cerebral autoregulation in humans. Am J Phys. 1998;274:H233-41.

14. Chiu CC, Yeh SJ. Assessment of cerebral autoregulation using time-domain cross-correlation analysis. Comput Biol Med. 2001;31:471-80.

15. Choi SH, Lee SJ, Rha KH, Shin SK, Oh YJ. The effect of pneumoperitoneum and Trendelenburg position on acute cerebral blood flow-carbon dioxide reactivity under sevoflurane anaesthesia. Anaesthesia. 2008;63:1314-8.

16. Doe A, Kumagai M, Tamura Y, Sakai A, Suzuki K. A comparative analysis of the effects of sevoflurane and propofol on cerebral oxygenation during steep Trendelenburg position and pneumoperitoneum for robotic-assisted laparoscopic prostatectomy. J Anesth. 2016;30:949-55.

17. Kalmar AF, Dewaele F, Foubert L, Hendrickx JF, Heeremans EH, Struys MM et al. Cerebral haemodynamic physiology during steep Trendelenburg position and $\mathrm{CO}_{2}$ pneumoperitoneum. $\mathrm{Br} J$ Anaesth. 2012:108:478-84.

18. Schramm P, Treiber AH, Berres M, Pestel G, Engelhard K, Werner C, et al. Time course of cerebrovascular autoregulation during extreme Trendelenburg position for robotic-assisted prostatic surgery. Anaesthesia. 2014;69:58-63.

19. Garrett ZK, Pearson J, Subudhi AW. Postural effects on cerebral blood flow and autoregulation. Phys Rep. 2017;5:e13150.

20. Ishiyama T, Kotoda M, Asano N, Ikemoto K, Shintani N, Matsuoka T, et al. Effects of hyperventilation on cerebral oxygen saturation estimated using near-infrared spectroscopy: a randomised comparison between propofol and sevoflurane anaesthesia. Eur J Anaesthesiol. 2016;33:929-35.

21. Aliane J, Duale C, Guesmi N, Baud C, Rosset E, Pereira B, et al Compared effects on cerebral oxygenation of ephedrine vs phenylephrine to treat hypotension during carotid endarterectomy. Clin Exp Pharmacol Physiol. 2017:44:739-48. 
22. Conti A, lacopino DG, Fodale V, Micalizzi S, Penna O, Santamaria LB. Cerebral haemodynamic changes during propofol-remifentanil or sevoflurane anaesthesia: transcranial Doppler study under bispectral index monitoring. Br J Anaesth. 2006;97:333-9.

23. Pater PM, Drummond JC. Cerebral physiology and the effects of anesthetic drugs. In: Miller RD, editor. Miller's Anesthesia, vol. 1. 7th ed. Philadelphia: Churchill Livingstone; 2010. p. 305-39.

24. Haydon GH, Dillon J, Simpson KJ, Thomas H, Hayes PC. Hypoxemia during diagnostic laparoscopy: a prospective study. Gastrointest Endosc. 1996;44:124-8.

25. Assad OM, El Sayed AA, Khalil MA. Comparison of volume-controlled ventilation and pressure-controlled ventilation volume guaranteed during laparoscopic surgery in Trendelenburg position. J Clin Anesth. 2016;34:55-61.

26. Kim MS, Soh S, Kim SY, Song MS, Park JH. Comparisons of pressurecontrolled ventilation with volume guarantee and volume-controlled 1:1 equal ratio ventilation on oxygenation and respiratory mechanics during robot-assisted laparoscopic radical prostatectomy: a randomized-controlled trial. Int J Med Sci. 2018;15:1522-9.

27. Davie SN, Grocott HP. Impact of extracranial contamination on regional cerebral oxygen saturation: a comparison of three cerebral oximetry technologies. Anesthesiology. 2012;116:834-40.

Ready to submit your research? Choose BMC and benefit from:

- fast, convenient online submission

- thorough peer review by experienced researchers in your field

- rapid publication on acceptance

- support for research data, including large and complex data types

- gold Open Access which fosters wider collaboration and increased citations

- maximum visibility for your research: over $100 \mathrm{M}$ website views per year

At $\mathrm{BMC}$, research is always in progress.

Learn more biomedcentral.com/submissions 